Vol. 1, No. 1, March 2019 e-ISSN: 2656-4882 p-ISSN: 2656-5935

\title{
Optimization of Wireless Network Performance Using the Hierarchical Token Bucket \\ (Case Study: Muhammadiyah University of Palembang)
}

\section{Optimasi Kinerja Jaringan Nirkabel Menggunakan Hierarchical Token Bucket}

(Studi Kasus: Universitas Muhammadiyah Palembang)

\author{
Yukos Pratama ${ }^{1}$, Usman Ependi ${ }^{2}$, Heri Suroyo ${ }^{3}$ \\ 1, 2,3 Informatics Department, Universitas Bina Darma \\ Jl. A. Yani No. 3 Seberang Ulu I, Palembang - Indonesia 30624 \\ Email: yukos@student.binadarma.ac.id ${ }^{1}$,u.ependi@binadarma.ac.id ${ }^{2}$,herisuroyo@binadarma.ac.id ${ }^{3}$
}

\begin{abstract}
Computer networks have penetrated into various fields including education for the learning process which is used as a medium for delivering scientific concepts to be more attractive and easily accepted. Muhammadiyah University of Palembang currently has very high mobility, both used for browsing information, downloading data and using other facilities. For the need for bandwidth management to manage each passing data so that the distribution of bandwidth becomes evenly distributed by using the queue tree method that is applied to the proxy. To evaluate internet bandwidth analyse QoS (Quality of Service) using typhoid standardization in terms of measurement of throughput, delay, and packet loss. The results of this study show that the quality of the network with the hierarchical token bucket method is more optimal, this is because the bandwidth will be divided according to the rules applied to bandwidth management and does not cause clients to fight over bandwidth.
\end{abstract}

Keywords: Computer network, HTB, QoS, Muhammadiyah University of Palembang.

\section{PENDAHULUAN}

Teknologi informasi saat ini khusunya jaringan komputer berkembang dengan sangat cepat seiring dengan kebutuhan masyarakat akan layanan yang memanfaatkan jaringan computer $\mathrm{Hal}$ ini bisa di lihat semakin banyaknya organisasi dan perusahaan yang menggunakan jaringan komputer untuk mempercepat arus informasi di dalam aktivitas sehari-hari. Perkembangan teknologi tidak lepas dari perkembangan teknologi jaringan, software maupun hardwarenya. Jaringan komputer dapat dikelompokan yang terdiri dari tiga jenis diantaranya adalah LAN (Local Area Network) MAN (Metropolitan Area Network) dan WAN (Wide Area Network). Kebutuhan akan koneksi internet

This work is licensed under a Creative Commons Attribution 4.0 International License. 
terutama jaringan hotspot sangat diminati oleh pengguna layanan internet, karena jaringan hotspot sangat relative mudah untuk diimplementasikandan memberikan kebebasan kepada penggunanya untuk dapat mengaksesnya kapan dan di mana saja melalui perangkat seperti Netbook, Laptop, Smart Phonedan yang lainnyaDalam membangun suatu jaringan komputer dibutuhkan teknik dalam bidang jaringan, namun pada kenyataannya tidak banyak orang menguasai pengetahuan tersebut dibandingkan dengan para pengguna internet. Untuk itu masih banyak dibutuhkan orang-orang yang dapat membangun suatu jaringan sampai dapat dimanfaatkan agar lebih baik lagi.

Pada perkembangan teknologi saat ini yang sering digunakan adalah jaringan wireless, yang memberikan banyak kemudahan dalam melancarkan komunikasi melalui media internet [1]. Wireless adalah daerah atau wilayah atau area dimana kita dapat terkoneksi ke jaringan internet melalui media wireless (nirkabel/tanpa kabel) menggunakan perangkat personal (PC) ataupun menggunakan perangkat bergerak (mobile)seperti notebook, ataupun smartphone yang memiliki wireless LAN dalam jangkauan area tertentu. Setiap perangkat WiFi atau biasa disebut dengan Access Point yang dijual dipasaran pasti memiliki sertifikasi WiFi. Tiaptiap perangkat ini memiliki standar yang berbeda-beda tergantung kemampuannya, akan tetapi saat ini sebagian besar telah menggunakan standar $802.11 \mathrm{n}$ [2].jaringan komputer merupakan sesuatu yang kita harus dijaga kestabilan operasionalnya. Untuk mengatasi masalah yang dihadapi dan supaya kondisi jaringan stabil, maka diperlukan adanya pengamatan jaringan yang baik. Tujuan dari pengamatan jaringan adalah memanfaatkan sumber daya yang terdapat pada suatu sistem jaringan komputer dengan semaksimal dan seefisien mungkin. Selain itu diharapkan dengan adanya pengamatan jaringan suatu sistem jaringan akan lebih mudah memantau atau memonitoring aktifitas yang ada di dalam sistem jaringan tersebut [3].Penerapan jaringan berbasis nirkabel harus memiliki sebuah standar layanan atau yang dikenal sebagai Quality of Services (QoS). QoS adalah kemampuan sebuah jaringan untuk menyediakan layanan trafik data yang melewatinya. Terdapat beberapa parameter yang dipakai untuk menentukan kualitas dari jaringan WLAN diantaranya Delay, Packet Loss dan Throughput [4]. Jaringan komputer bisa dinilai bagus dapat diketahui dengan QoS (Quality of Service) jaringan tersebut. QoS (Quality of Service) adalah suatu teknologi yang dapat diimplemetasikan kedalam sebuah jaringan komputer agar dapat memberikan kualitas layanan yang optimal dan merata bagi para pengguna jaringan komputer. QoS memungkinkan admin jaringan agar dapat menyelesaikan berberapa dampak akibat terjadinya kemacetan (congestion) pada lalu lintas aliran paket di dalam sebuah jaringan. Quality of Service (QoS) adalah metode untuk mengukur seberapa baik sebuah jaringan dan merupakan suatu tindakkan untuk menerapkan karakteristik dan sifat dari satu service dalam sebuah jaringan [5]. Manajemen bandwidth merupakan teknik pengelolaan jaringan sebagai usaha untuk memberikan performa jaringan yang adil dan memuaskan. Manajemen bandwidth juga digunakan untuk memastikan 
bandwidth yang memadai untuk memenuhi kebutuhan traffic data dan informasi serta mencegah persaingan antara aplikasi. sebenarnya management bandwidht adalah satu hal yang wajib bagi jaringan multi layanan, semakin banyak dan varian aplikasi yang dapat dilayani oleh suatu jaringan akan mempengaruhi pada penggunaan dalam suatu jaringan tersebut. Link-link yang ada harus mampu menangani kebutuhan user akan aplikasi tesebut bahkan dalam keadaan kongesti sekalipun Ada beberapa metode yang dapat diterapkan untuk mengimplementasikan bandwith manajement ini diantaranya melalui proxy server, QoS atau traffic shapping, atau pembatasan bandwith atau limited [6].

Metode manajemen bandwidth HTB (Hierarchy Token Bucket) merupakan teknik antrian yang dapat memberikan pembatasan trafik pada setiap level maupun klasifikasi. Dengan manajemen HTB ini, bandwidth yang tidak terpakai bisa digunakan oleh klasifikasi yang lebih rendah. HTB termasuk dalamClassfull Queueing Discipline yaitu suatu metode antrian dengan multiple class, sehingga dimungkinkan konfigurasi yang berbeda untuk setiap kelasnya. Dengan manajemen bandwidth diharapkan kualitas koneksi dalam jaringan yang dapat diartikan sebuah proses pengiriman data hingga sampai pada tujuan dengan kualitas koneksi yang lebih baik menjadi penilaian Quality of Serviceyang dapat dievaluasi [7]. jaringan komputer memiliki beberapa jenis ganguaan atau masalah, seperti contohnya masalah bandwidth, trougphut dan dealy, yang bisa membuat layanan cukup terganggu bagi banyak aplikasi. salah satu contohnya komunikasi panggilan suara (VoIP atau IP Telephony) serta menonton video online dapat membuat pengguna menjadi kesal ketika paket data aplikasi tersebut dialirkan di atas jaringan dengan bandwidth yang kurang memenuhi latency yang tidak dapat dikendalikan, atau jitter yang berlebih. layanan Quality of Service (QoS) ini bisa menyebabkan bandwidth,trouphput, dan delay dapat diprediksi dan dicocokkan dengan kebutuhan aplikasi yang digunakan di dalam jaringan tersebut.

\section{METODOLOGI PENELITIAN}

\subsection{Metodologi Penelitian}

Metode penelitian disini menggunakan metode Action Research (AR), metode tindakan bertujuan bahwa teori dan praktik dapat secara tertutup diintegrasikan dangan pembelajaran dari hasil intervensi yang direncanakan setelah diagnosis yang rinci terhadap konteks masalahnya. Action research adalah salah satu cara atau proses perbaikan sesuatu yang evaluasi pelaksanaan, perencanaan, dan dilakukan secara sistematik dan sistematik agar mendapatatkan validitas dan reliabilitasnya untuk mencapai tingkatan riset [8]. Untuk pengukuran QoS metodenya terdiri dari beberapa parameter bandwidth, throughput, delay, dan paket loss dari user pengirim sampai ke user penerima atau bisa disebut juga 
dari ujung ke ujung (end to end) [9]. Dengan mengacu pada model penelitian ini penulis melakukan pendekatan dalam kegiatan penelitian yaitu [10]:

a) Melakukan diagnosa (diagnosing)

b) Membuat rencana tindakan (action planning)

c) Melakukan tindakan (action taking)

d) Melakukan evaluasi (evaluating)

e) Pembelajaran (learning)

\subsection{Metodelogi Pengumpulan Data}

Adapun metode pengumpulan data yang penulis pergunakan adalah sebagai berikut [11]:

a) Pengamatan (Observasi)

Yaitu metode pengumpulan data dengan cara mengadakan tinjauan atau pengamatan secara langsung ke objek yang diteliti. Observasi dilakukan langsung pada Universitas Muhammadiyah Palembang dengan cara mengamati kinerja jaringan yang ada.

b) Pengujian (Testing)

Data yang diperoleh dari hasil pengujian lansung pada system jaringan Universitas Muhammadiyah Palembang dengan melakukan beberapa tahap pengujian sehingga memperoleh data yang efektif.

c) Studi Kepustakaan

Di lakukan berdasarkan pengetahuan teoritis yang telah di terima penulis selama masa perkuliahan serta membaca buku-buku yang ada hubungannya dengan penyusunan skiripsi ini yaitu data yang diperoleh dari perpustakaan dan dokumentasi.

\subsection{Paramater Kualitas Jaringan}

Ada 4 karakteristik untuk melakukan kualitas jaringan [12] :

a) Bandwidth

Secara umum pengertian bandwidth adalah perbedaan angka antara komponen sinyal berfrekuensi rendah dan sinyal berfrekuensi tinggi atau dapat juga disebut lebar dari cakupan frekuensi yang digunakan sinyal di dalam sebuah medium transmisi. Selain itu, secara umum bandwidth dapat juga diartikan sebagai jumlah data yang dapat dikirimkan melalui saluran komunikasi dalam jangka waktu tertentu [13].

b) Delay

Delay merupakan lamanya waktu yang dibutuhkan oleh data atau informasi untuk sampai ke tempat tujuan data atau informasi tersebut dikirim. Delay pada suatu jaringan akan menentukan langkah apa yang akan kita ambil ketika kita memanajemen suatu jaringan. Ketika Delay besar, dapat diketahui jaringan tersebut sedang sibuk atau kemungkinan yang lain adalah kapasitas jaringan tersebut yang kecil 
Vol. 1, No. 1, March 2019

sehingga bisa melakukan tindakan pencegahan agar tidak terjadi overload.

Tabel 1. Standarisasi Delay

\begin{tabular}{lc}
\hline \multicolumn{1}{c}{ Kategori } & Delay \\
\hline Sangat Bagus & $<150 \mathrm{~ms}$ \\
Bagus & $150 \mathrm{~s} / \mathrm{d} \mathrm{300} \mathrm{\textrm {ms }}$ \\
Sedang & $300 \mathrm{~s} / \mathrm{d} \mathrm{s} / \mathrm{d} 450 \mathrm{~ms}$ \\
Jelek & $>450 \mathrm{~ms}$ \\
\hline
\end{tabular}

d) Packet Loss

Packet Loss merupakan banyaknya paket yang gagal mencapai tempat tujuan paket tersebut dikirim. Ketika Packet Loss besar maka dapat diketahui bahwa jaringan sedang sibuk atau terjadi overload. Packet Loss mempengaruhi kinerja jaringan secara langsung. Ketika nilai Packet Loss suatu jaringan besar, dapat dikatakan kinerja jaringan tersebut buruk.

Tabel 2. Standarisasi Packet Loss

\begin{tabular}{lc}
\hline \multicolumn{1}{c}{ Kategori } & Packet Loss \\
\hline Sangat Bagus & $0 \%$ \\
Bagus & $3 \%$ \\
Sedang & $15 \%$ \\
Jelek & $25 \%$ \\
\hline
\end{tabular}

e) Troughput

Kemampuan troughput dalam menopang hardware (perangkat keras) disebut dengan bandwidth. Kecepatan data rata - rata yang diterima oleh suatu node dalam selang waktu pengamatan tertentu. Dimana kita sedang

Tabel 3. Standarisasi troughput

\begin{tabular}{lc}
\hline \multicolumn{1}{c}{ Kategori } & Troughput \\
\hline Sangat Bagus & $100 \%$ \\
Bagus & $75 \%$ \\
Sedang & $50 \%$ \\
Jelek & $25 \%$ \\
\hline
\end{tabular}

\section{HASIL DAN PEMBAHASAN}


Hierarcbical Token Bucket (HTB) Konfigurasi HTB sebenarnya telah dilakukan hanya dengan membuat queue. Akan tetapi, HTB memiliki fungsi sebagai penyedia ekstra bandwidth yang diberikan persatuan waktu. Dengan mengatur bucket size, maka ekstra bandwidth akan didapatkan. Sebenarnya bucket size default telah diisi dengan nilai 0.1 akan tetapi nilai tersebut tidak akan memberikan ekstra bandwidth kepada client atau user. Ekstra bandwidth akan didapatkan jika bucket size bernilai lebih dari $1(>1)$ atau bucket capacity lebih dari MIR, karena bandwidth akan diterima client dari bucket capacity yang dapat diketahui dari hasil perkalian antara MIR (Max-Limit) * Bucket Size. Jika bucket size bernilai 0.1 maka bucket capacity bernilai lebih kecil dari MIR yang menyebabkan bandwidth yang diberikan mengacu pada max-limit yang diberikan. Akan tetapi jika mengatur bucket size dengan nilai lebih dari 1, maka bucket capacity lebih besar dari max-limit yang menyebabkan bandwidth menjadi lebih besar dari maxlimit. Konsep token bucket mirip seperti konsep menabung tanpa bunga. Berikut konfigurasi yang dilakukan pada mikrotik.

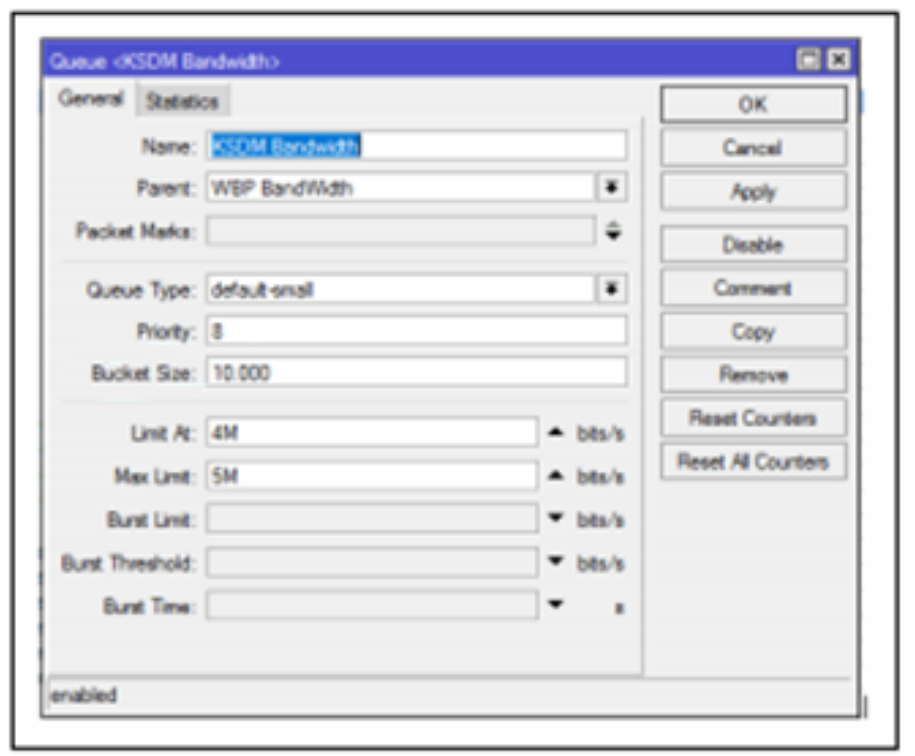

Gambar 1. Konfigurasi Hierarchical Token Bucket (HTB)

Hasil dari pengukuran parameter Quality of service (Qos)jaringan komputer pada Universitas Muhammadiyah Palembang dengan mengunakan metode hierarchical token bucket dan pengukuran mengunakan software AxenceNetTools untuk mengukur parameter troughput, delay dan packet loss dan Ookla speedtest untuk mengukur parameter bandwidth[14]. Mekanisme pengukuran dengan menguji setiap fakultas pada Universitas ppMuhammadiyah Palembang dengan menguji test ip address local yaitu detik.com dan internasional meliputi facebook dan youtube setelah mendapatkan mendapatkan 
hasil dari pengukuran bandwidth, troughput, delay dan packet loss maka tahap selanjutnya yang akan di lakukan peneliti adalah melakukan evaluasi terhadap apa yang telah di ukur untuk mengetahui kualitas layanan jaringan LAN berdasarkan standart TIPHON [15] [16].

\subsection{Bandwidht}

Dari hasil pengukuran kecepatan bandwidth yang dilakukan selama empat hari dimana satu hari dilakukan dua kali pengukuran pada pagi hari 9:30 sampai dengan 11:30 wib dan pada siang hari dilakukan pada pukul 13:30 sampai dengan 15:30 wib didapatkan hasil rata-rata kecepatan bandwidth sebagai berikut:

Tabel 4. Bandwidht

\begin{tabular}{|c|c|c|c|c|}
\hline No & Hari /Tanggal & Waktu & Download & Upload \\
\hline 1 & Senin 08 Oktober 2018 & $\begin{array}{l}09: 30-11: 30 \\
1: 30-15: 30\end{array}$ & 0,19 & 1,33 \\
\hline 2 & Selasa 09 Oktober 2018 & $\begin{array}{l}09: 30-11: 30 \\
1: 30-15: 30\end{array}$ & 0,63 & 0,91 \\
\hline 3 & Rabu 10 Oktober 2018 & $\begin{array}{l}09: 30-11: 30 \\
1: 30-15: 30\end{array}$ & 6,45 & 0,32 \\
\hline 4 & $\begin{array}{l}\text { Kamis } 11 \text { Oktober } \\
2018\end{array}$ & $\begin{array}{l}09: 30-11: 30 \\
1: 30-15: 30\end{array}$ & 3,5 & 4,76 \\
\hline
\end{tabular}

Tabel 4 adalah nilai pengukuran rata-rata bandwidth di area masjid Universitas Muhammadiyah Palembang parameter pengujian bandwidth meliputi kecepatan download dan upload dengan satuan Mbps. Disimpulkan meliputi kecepatan downlaod paling tinggi yaitu pada hari rabu 10 Oktober 2018 6,45 Mbps dan paling rendah pada hari senin 08 Oktober 2018 sebesar 0,19 Mbps sedangkan nilai upload tertinggi pada hari Kamis 11 Oktober sebesar 4,76 dan yang terendah pada hari rabu 10 Oktober 2018 sebesar 0,32

\subsection{Trouhput}

Rata-rata throughputdalam satuan bps yang dapat disimpulkan bahwa troughput terkecil adalah pada hari selasa 09 Oktober 2018 dengan pengujian ke server Detik.com sebesar 95597 bps dan troughput terbesar adalah pada hari Senin 08 Oktober 2018 dengan pengujian ke server Detik.com sebesar 380265.

Tabel 5. Standarisasi troughput

\begin{tabular}{|c|c|c|c|c|}
\hline No & $\begin{array}{c}\text { Hari / } \\
\text { Tanggal }\end{array}$ & Website & Rata- Rata & $\%$ \\
\hline
\end{tabular}


Vol. 1, No. 1, March 2019

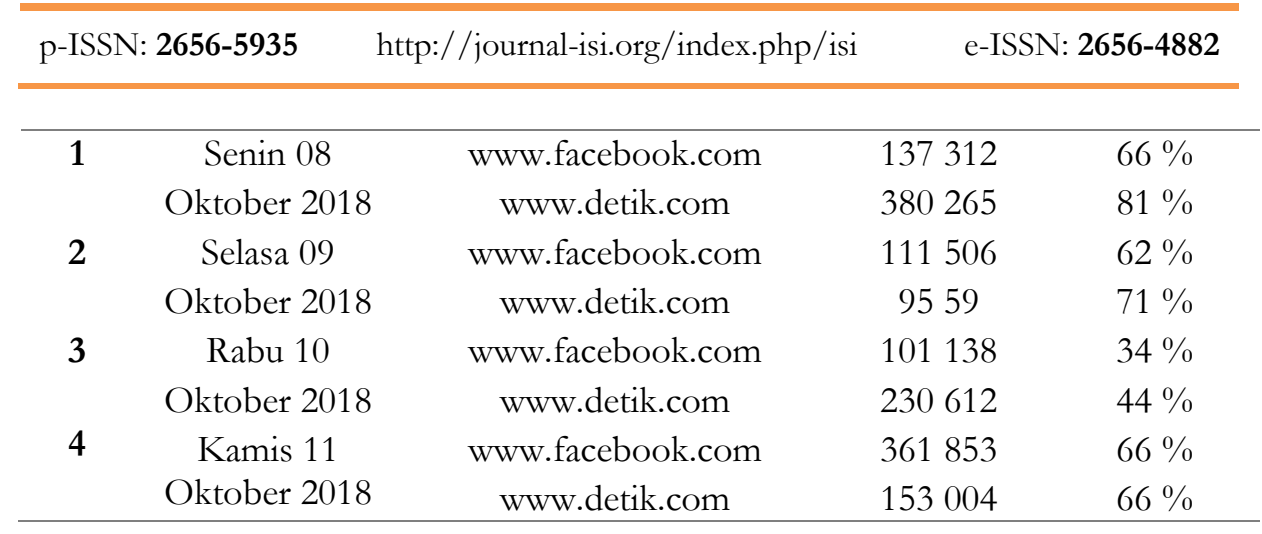

Berdasarkan standarisasi TIPHON untuk Throughput maka didapat kesimpulan sebagai berikut.

1. Hasil pengukuran Facebook.com adalah 177952 bps dengan persentase $57 \%$ berkategori Sedang.

2. Hasil pengukuran Detik.com adalah 214869 bps dengan persentase 65,5\% berkategori Sedang.

\subsection{Packet Loss}

Dari TabelRata-rata Packet Loss dibawah ini bisa disimpulkan bahwa jumlah paket data yang hilang paling sedikit terjadi pada hari senin pada tangga 08 Oktober 2018 dengan pengujian ke server youtube dan detik.com dengan persentase $17 \%$ sedangkan persentase paket data yang paling banyak hilang terjadi pada pada hari rabu 10 Oktober 2018 dengan penggujian ke server youtube dan detik.com dengan persentase sebesar $46 \%$.

Tabel 6. Standarisasi packet loss

\begin{tabular}{|c|c|c|c|c|c|}
\hline No & $\begin{array}{c}\text { Hari / } \\
\text { Tanggal }\end{array}$ & Website & Sent & loss & $\%$ loss \\
\hline \multirow[t]{3}{*}{1} & Senin 08 & www.facebook.com & 2337 & 555 & $17 \%$ \\
\hline & $\begin{array}{c}\text { Oktober } \\
2018\end{array}$ & www.detik.com & 2355 & 554 & $17 \%$ \\
\hline & Selasa 09 & www.facebook.com & 2720 & 897 & $31 \%$ \\
\hline \multirow[t]{2}{*}{2} & $\begin{array}{c}\text { Oktober } \\
2018\end{array}$ & www.detik.com & 2812 & 817 & $27 \%$ \\
\hline & Rabu 10 & www.facebook.com & 4046 & 2298 & $46 \%$ \\
\hline \multirow[t]{2}{*}{3} & $\begin{array}{c}\text { Oktober } \\
2018\end{array}$ & www.detik.com & 4048 & 2268 & $46 \%$ \\
\hline & Kamis 11 & www.facebook.com & 5223 & 1480 & $28 \%$ \\
\hline 4 & $\begin{array}{c}\text { Oktober } \\
2018\end{array}$ & www.detik.com & 5239 & 1386 & $26 \%$ \\
\hline
\end{tabular}


Berdasarkan standarisasi nilai packet loss versi TIPHON, maka bisa disimpulkan sebagai berikut.

1. Hasil pengukuran youtube.com adalah $30,5 \%$ untuk kategori Jelek.

2. Hasil pengukuran detik.com adalah $29 \%$ untuk kategori Jelek

\subsection{Delay}

Pada tabel rata-rata delay dibawah ini disimpulkan bahwa penundaan paket data menuju server youtube paling banyak terjadi pada hari selasa 09 Oktober 2018 sebesar 411 dan yang menuju server detik paling banyak terjadi pada hari selasa 09 Oktober 2018 sebesar 381.

Tabel 7. Standarisasi delay

\begin{tabular}{cccccc}
\hline No & $\begin{array}{c}\text { Hari / } \\
\text { Tanggal }\end{array}$ & Website & Min & Max & $\begin{array}{c}\text { Rata- } \\
\text { rata }\end{array}$ \\
\hline $\mathbf{1}$ & Senin 08 & www.facebook.com & 19 & 983 & 229 \\
& Oktober & www.detik.com & 12 & 984 & 211 \\
& 2018 & & & & \\
$\mathbf{2}$ & Selasa 09 & www.facebook.com & 50 & 999 & 411 \\
& Oktober & www.detik.com & 15 & 999 & 381 \\
& 2018 & & & & \\
$\mathbf{3}$ & Rabu 10 & www.facebook.com & 19 & 996 & 363 \\
& Oktober & www.detik.com & 12 & 998 & 332 \\
& 2018 & & & & \\
$\mathbf{4}$ & Kamis 11 & www.facebook.com & 18 & 919 & 297,5 \\
& Oktober & www.detik.com & 13 & 883 & 295 \\
& 2018 & & & & \\
\hline
\end{tabular}

Berdasarkan standarisasi nilai delay versi TIPHON, maka bisa disimpulkan sebagai berikut.

1. Hasil pengukuran youtube.com adalah $325 \mathrm{~ms}$ untuk kategori Sedang.

2. Hasil pengukuran detik.com adalah 304,75 ms untuk kategori Sedang.

\section{KESIMPULAN DAN SARAN}

\subsection{Kesimpulan}

Kesimpulan yang telah didapat setelah melakukan tahapan-tapahan pada penelitian ini adalah sebagai berikut.

1. Dalam penelitian QoS pada waktu pagi hari lebih banyak pengguna dibandingkan pada siang hari

2. Pada saat menggunkan metode htb lebih baik karena pembagian bandwidth merata dan keseluru user 
3. Faktor-faktor yang mempengaruhi QoS pada Universitas Muhammadiyah Palembang adalah redaman, distorsi dan juga kapasitas bandwidth yang tersedia juga mempengaruhi kinerja QoS

\subsection{Saran}

Adapun saran penulis setelah melakukan penelitian ini adalah sebagai berikut ini.

1. Menambah titik access point agar tidak terjadi penumpukan dalam satu titik dan menembahkan repeater agar sehingga sinyal lebih stabil

2. Sebaiknya melakukan perhitungan ulang untuk penempatan access point untuk mengurangi redaman dan distorsi.

3. Sebaiknya pengukuran jaringan dilakukan setiap bulan oleh pihak Universitas Muhammadiyah Palembang untuk meningkatkan kualitas jaringan

\section{DAFTAR PUSTAKA}

[1] A. Kinerja et al., "Wireless Local Area Network ( Wlan )," vol. 4, no. 1, pp. 47-61, 2016.

[2] D. I. Haerudin, L. B. Aksara, and M. Yamin, "Implementasi Wireless Distribution System (Wds) Pada Hotspot (Studi Kasus: Smk Negeri 1 Kendari)," semanTIK, vol. 3, no. 2, pp. 105-112, 2017.

[3] M. H. S. Abidin and Y. Ardian, "Rancang Bangun Aplikasi Monitoring Network Berbasis Web Menggunakan Html5,” Tek. Inform., pp. 1-7, 2015.

[4] D. Wisely, P. Eardley, and L. Burness, "Analisis Quality Of Service (QoS) Jaringan Internet Berbasis Wireless Lan Pada Layanan Indihome," IP $3 G$, vol. 3, no. 3, pp. 201-248, 2017.

[5] A. Emrul, M. Yamin, L. Surimi, J. T. Informatika, F. Teknik, and U. Halu, "Analisis Quality of Service (QoS) Kinerja Sistem Hotspot Pada Routerboard Mikrotik 951Ui-2HnD Pada Jaringan Teknik Informatika," vol. 3, no. 2, pp. 87-94, 2017.

[6] M. W. Zamuswara, P. N. Jakarta, and I. Pendahuluan, "Manajemen Bandwidth Menggunakan Metode Hierarchical Token Bucket ( HTB ) P ada Jaringan LAN PT . Waskita Beton Precast Plant Karawang,” pp. 1-7.

[7] H. Oktafiandi, Widyawan, and S. S. Kusumawardani, "Rancang Bangun Manajemen Bandwidth Pada Wireless Mesh Network Dengan Metode," Semin. Nas. Teknol. Inf. dan Multimed., pp. 6-8, 2015.

[8] A. Muzakir and C. D. Kusmindari, "Design of Push-Up Detector Applications Using Quality Function Development and Anthropometry For Movement Error Detection," Sci. J. Informatics, vol. 5, no. 2, pp. 248-257, 2018.

[9] P. Studi, T. Infortika, F. I. Komputer, and U. D. Nuswantoro, "Action Research Pada Dinas Perhubungan Komunikasi Dan Informasi Kabupaten 
Pemalang," pp. 1-10, 2015.

[10] Y. A. Pranata, I. Fibriani, and S. B. Utomo, "Analisis Optimasi Kinerja Quality Of Service Pada Layanan Komunikasi Data Menggunakan NS - 2 di PT . PLN ( PERSERO ) Jember," Sinergi, vol. 20, no. 2, pp. 149-156, 2016.

[11] T. D. Purwanto and A. Wijaya, "Evaluasi Aplikasi Exploid Wifi Di Tingkat Availability Dan Vulnerability," Simetris J. Tek. Mesin, Elektro dan Ilmu Komput., vol. 8, no. 2, p. 801, 2017.

[12] S. Informasi, "PROSIDING seminar nasional sisfotek Evaluasi Quality of Service Jaringan Internet (Studi Kasus: RS Kusta Dr . Rivai Abdullah Palembang)," vol. 3584, pp. 186-192, 2011.

[13] Risna, Isnawaty, and Sutardi, "Optimalisasi Jaringan Wireless Dan Analisis Quality of SERVICE (QoS) Menggunakan Metode Hierarchical Token Bucket (HTB)," semanTIK, vol. 3, no. 2, pp. 59-68, 2017.

[14] E. Ronald, S. Moningkey, and P. Kapele, "Analisa Quality of Service (QOS) Jaringan Komputer di SMK Kristen I Tomohon,” vol. 5, no. 1, 2017.

[15] A. Desy, N. Utomo, and A. Ashari, "Manajemen Bandwidth Menggunakan Metode PCC pada Jaringan LAN Fakultas Bisnis dan Teknologi Universitas Teknologi Yogyakarta," vol. 2, no. 1, 2018.।

[16] U. Ependi, Fatoni and R. Rasmayora, "IMPLEMENTASI MANAJEMEN BANDWIDTH DAN PROXY SERVER PADA JARINGAN KOMPUTER PT. CNG," EMNASTEKNOMEDIA ONLINE, vol. 2, no. 1, pp. 1-05, 2014. 